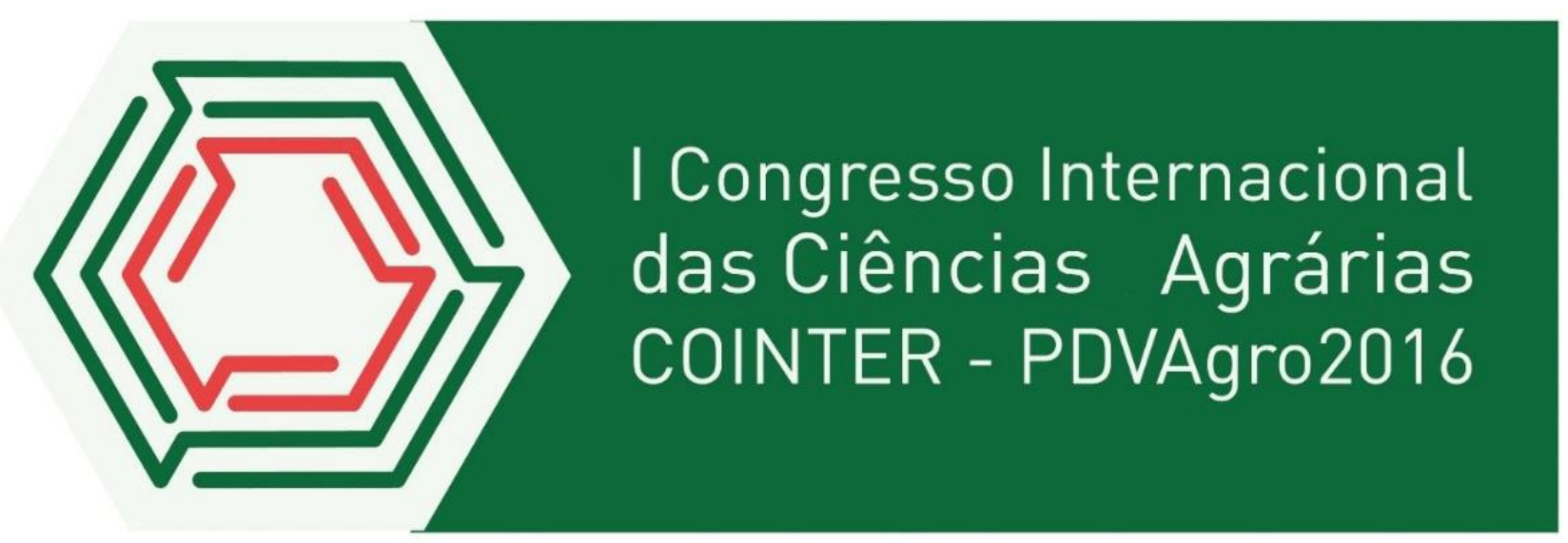

\title{
FUNDO ROTATIVO SOLIDÁRIO COM BASE NA CRIAÇÃO DE SUÍNOS
}

\author{
Apresentação: Relato de Experiência \\ Maria José Felipe Filha ${ }^{1}$; Andressa Alves Guimarães Rodrigues ${ }^{2}$; Aline Carneiro de Paula ${ }^{3}$ \\ Alzira Josefa de Siqueira Medeiros ${ }^{4}$
}

\section{Introdução}

Em 1993, no Cariri Paraibano, na Comunidade Rural de Caiçara, município de Soledade surgiu o fundo rotativo solidário (...) a palavra "solidário" confere um novo sentido de sociedade, com estilo e valores concebidos e apropriados localmente, mas abertos à interação com outros grupos e ideais e contrapondo-se às realidades políticas e econômicas excludentes (ROCHA \& COSTA, 2006, p. 13).

A criação de suínos é uma atividade com predomínio em pequenas e médias propriedades rurais brasileiras, sendo que $81,7 \%$ dos suínos são criados em unidades de até 100 hectares. A atividade encontra-se presente em 46,5\% dos 5,8 milhões de propriedades existentes no país, empregando mão-de-obra familiar, constituindo importante fonte de renda e um dos fatores de estabilidade social no meio rural (ANUALPEC 2001).

O presente trabalho teve por objetivo relatar a experiência dos criadores e criadoras de suínos da comunidade Tobias Ribeiro no município de Juarez Távora- PB, que encontraram na dinâmica do

\footnotetext{
${ }^{1}$ Estudante do curso de Bacharelado Agroecologia, Universidade Federal da Paraíba (UFPB), Centro de Ciências Humanas, Sociais e Agrárias (CCHSA), mariaregis33@ hotmail.com

${ }^{2}$ Licenciada em Ciências Agrárias UFPB/CCHSA, andrezaalves01@ hotmail.com

${ }^{3}$ Mestranda em Ciências Agrárias (Agroecologia), UFPB/CCHSA, alinecarneiro_paula@ hotmail.com

${ }^{4}$ Socióloga e educadora popular CEFES-NE, alzirasmedeiros@ gmail.com
} 
Fundo Rotativo Solidário, uma forma de melhoria da qualidade de vida comunitária a partir do trabalho solidário.

\section{Relato de Experiência}

A coleta de informações foi através de registros encontrados com o grupo, como relatórios e atas, como também entrevistas individuais realizadas com alguns participantes FRS. Em seguida foi realizada uma reunião com grupo produtivo, essa teve como objetivo dialogar com o grupo sobre sua história.

Foram realizadas também visitas as instalações (Figura 1), onde foi possível observar todo o manejo da criação. A organização do grupo produtivo nasceu com o incentivo do projeto de geração de renda do Vencer Juntos, que foi implantado no ano de 2010, na comunidade Tobias Ribeiro, esse projeto era voltado para famílias que trabalhavam no campo, tendo como objetivo de fortalecer a agricultura familiar, promovendo ações e formações que contribuíssem para geração de renda e empoderamento das comunidades rurais. Foram beneficiárias desse projeto cinco famílias.

Figura 1. Visita às instalações do grupo produtivo, Juarez Távora-PB, 2015.

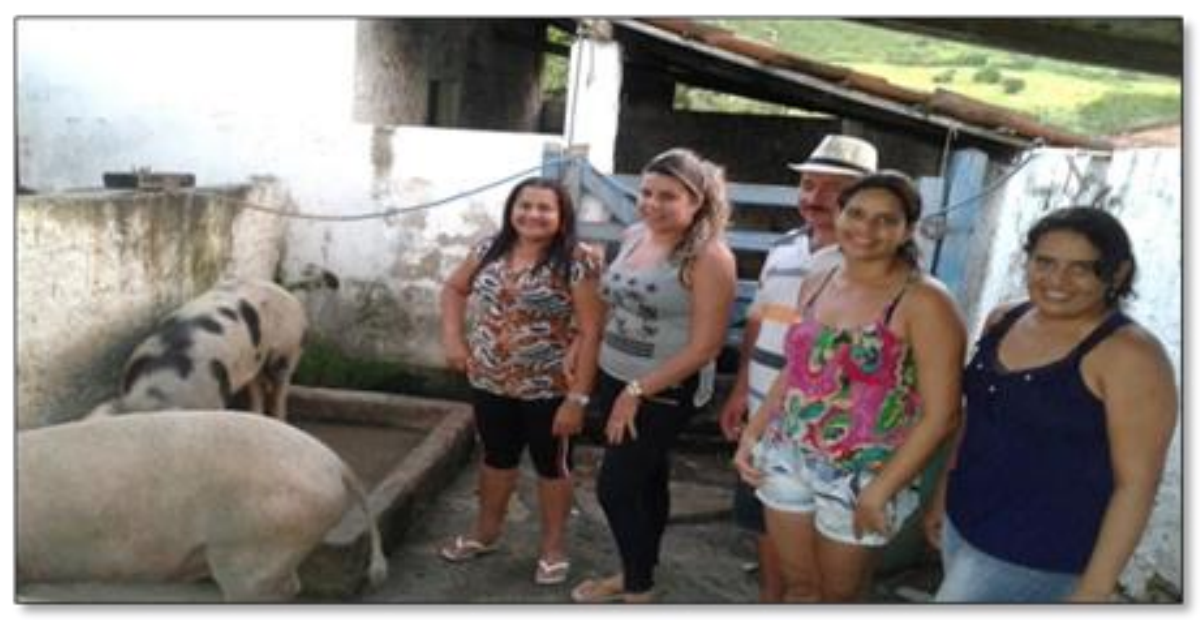

A Diocese do município de Guarabira-PB financiou o projeto, mas o grupo era responsável pela a manutenção do FRS na comunidade. Inicialmente uma das metas do grupo era aumentar a oferta de suínos para açougues existentes no município. Cada família recebeu um recurso financeiro para compra de animais, tendo uma carência de seis meses para o retorno do recurso ao FRS, todos os participantes do grupo devolveram esse, após as venda dos animais. Foi relatado também que o grupo se reunia com frequência, com o compromisso de dialogar sobre o FRS e realizar avaliação 
do trabalho mensal do grupo.

A divisão das tarefas entre os participantes do grupo ocorria de forma organizada, distribuídas revesadamente de forma igual entre todos desde o processo da criação, ao abate, a refrigeração até o ponto de venda da carne. Gerando assim, uma renda solidária para todo grupo, ficando na comunidade esse recurso financeiro de forma a gerar mais renda no comércio local, beneficiando os agricultores e consumidores de forma solidária e preços justos. Sendo essa renda significativa para sobrevivência das pessoas contribuindo para a permanência delas na comunidade. Através do Fundo Rotativo Solidário as famílias conseguiram melhorar sua renda. Com o trabalho coletivo conseguiram instalar um abatedouro com uma câmera fria e um frigorífico no município, onde fornecem carne suína de boa qualidade e sem uso de aditivos na ração.

\section{Considerações}

Os FRS são uma alternativa para democratização do trabalho coletivo, integrando-se com o fortalecimento das potencialidades da comunidade. Porém, para que ele possa funcionar, é necessário que os participantes aceitem a sua proposta, já que os FRS só funcionam se houver cooperação e devolução continua dos recursos.

\section{Referências}

ANUALPEC. 2001. Anuário da Pecuária Brasileira (ANUALPEC). Editorial Argos Comunicação. Pg. 359.

ROCHA, J. C. da e COSTA, J. W. de S. Fundo Rotativo Solidário: instrumento de promoção da agricultura familiar e do desenvolvimento sustentável no semiárido. Agriculturas, Rio de Janeiro: AS-PTA, vol. 2, n. 3, p. 12-15, out. 2005. 